\title{
Modification of carbon nanotubes by ball-milling to be used as ozonation catalysts
}

O.S.G.P. Soares ${ }^{1, *}$, A.G. Gonçalves ${ }^{1}$, J.J. Delgado ${ }^{2}$, J.J.M. Órfão ${ }^{1}$, M.F.R. Pereira ${ }^{1}$

1 - Laboratório de Catálise e Materiais (LCM), Laboratório Associado LSRE/LCM, Departamento de Engenharia Química, Faculdade de Engenharia da Universidade do Porto, Rua Dr. Roberto Frias, 4200-465 Porto, Portugal

2 - Departamento de Ciência de los Materiales e Ingeniería Metalúrgica y Química Inorgánica, Facultad de Ciencias, Universidade de Cadiz, Campus Rio San Pedro, 11510 Puerto Real, Cadiz, Spain

salome.soares@fe.up.pt, agg@fe.up.pt; juanjose.delgado@uca.es; jjmo@fe.up.pt, fpereira@fe.up.pt

Corresponding author: salome.soares@fe.up.pt 


\section{Abstract}

The influence of ball-milling in the texture and surface chemistry of multi-walled carbon nanotubes (MWCNT) was studied in this work. Treatment times up to $360 \mathrm{~min}$ at constant frequency (15 vibrations/s) and frequencies from 10 to 20 vibrations/s during $30 \mathrm{~min}$ were used for the preparation of the modified samples. These were characterized by nitrogen adsorption at $-196{ }^{\circ} \mathrm{C}$, temperature programmed desorption (TPD), X-ray photoelectron spectroscopy (XPS) and transmission electron microscopy (TEM). The milled samples were used as catalysts for the ozonation of oxalic acid. The surface area of the MWCNT increases, whereas the particle size decreases with the ball-milling time until $240 \mathrm{~min}$ at 15 vibrations/s. The functionalization of MWCNT surface is not achieved by ball-milling under the conditions used. The catalytic performance of the ball-milled samples for oxalic acid mineralization increased significantly when compared to the unmilled MWCNT. Therefore, ball-milling is an effective and simple method to increase the surface area of commercial carbon nanotubes without significant changes of their structural properties, and, consequently, this method allows increasing their catalytic performance in ozonation processes.

Keywords: carbon nanotubes, ball-milling, textural properties, ozonation, oxalic acid 


\section{Introduction}

Carbon nanotubes (CNTs) have shown promising potential for application in many engineering fields, due to their particular electronic and physical properties [1]. The morphology of the CNTs is important for specific applications. For some electronic or structural applications, long CNTs are required to be used as strong and conducting nanocables. However, for many other applications such as chemical or energy-storage, it is desirable to have short nanotubes with open tips to enhance the active surface area and facilitate diffusion and chemical reactions [2]. Several methods have been used to obtain short and opened CNTs, including acid treatment, ultrasonication, scanning tunnelling microscope nanostructuring, lithographic methods and ball-milling. Among them, ball-milling have attracted much attention as a promising way for modifying carbon nanotubes, namely to adjust lengths and open the closed ends [2-4]. However, the surface properties of the CNTs can be dependent on the opening methods. By ball-milling, multiwalled carbon nanotubes (MWCNT) can be transformed into curved nanotubes [5], nanoparticles [6], short and open-tipped nanotubes [4], but also in amorphous as well as disrupted tubular structure when prolonged ball-milling is applied [2, 7]. Tucho et al. [3] studied the effect of ball-milling intensity on morphology of MWCNT and observed that open and short MWCNT can be generated by tuning ball-milling intensity .

Catalytic ozonation is an innovative technology for the removal of organic pollutants in water and wastewater. Ozone preferentially attacks molecules containing unsaturated bonds, leading to the formation of saturated compounds such as aldehydes, ketones and carboxylic acids. Due to their low reactivity towards ozone, these compounds tend to accumulate in water. Therefore, ozonation by itself is not sufficient to achieve a high mineralization degree. To overcome this drawback, ozonation processes are being modified in order to increase their oxidizing capability. Heterogeneous catalytic ozonation, which is one of the most attractive alternatives, aims to enhance the removal of highly refractory compounds by the transformation of ozone into more reactive species and/or adsorption and reaction of the pollutants on the surface of the catalyst [8].

Carbon nanotubes have been appointed as a very promising material for catalytic applications [1]. The interest in the use of this material in ozonation processes has been increasing recently due to the good results observed [9-12]. Samples of 
commercial MWCNT and carbon nanotubes functionalized by oxidation both in liquid and gas phase have proved to efficiently perform as ozonation catalysts [9-11, 13-16]. In this work, the influence of the milling time on the MWCNT properties (texture, morphology, structure and surface chemistry) was investigated. Milled samples were used as catalysts for the ozonation of oxalic acid, which is the most common final oxidation product of a vast number of organic compounds and is refractory to single ozonation [8, 17]. Moreover, it is a quite simple molecule and, therefore, it was chosen as a model compound for more detailed studies. The results were compared with those obtained in the presence of the pristine MWCNT sample, previously reported [11].

\section{Experimental}

\subsection{Preparation of materials}

A commercial multi-walled carbon nanotube (MWCNT) sample (Nanocyl 3100) was used as starting material. According to the supplier, these nanotubes have an average diameter of $9.5 \mathrm{~nm}$, an average length of $1.5 \mu \mathrm{m}$ and carbon purity higher than $95 \%$. In order to obtain the modified samples, the commercial carbon nanotubes were ball milled in a Retsch MM200 equipment under different milling conditions. Times up to $360 \mathrm{~min}$ at constant vibration frequency (15 vibrations/s) and vibration frequencies from 10 to 20 vibrations/s during $30 \mathrm{~min}$ were used for the preparation of the modified samples (identification of the samples: $B M \_X \_Y$, where $X$ is the time in minutes and $Y$ is the frequency in vibrations/s).

\subsection{Characterization of materials}

The texture, morphology and surface chemistry of the samples were characterized by nitrogen adsorption, particle size distribution, transmission electron microscopy (TEM), temperature programmed desorption (TPD) and X-ray photoelectron spectroscopy (XPS).

The textural characterization of the samples was based on the $N_{2}$ adsorption isotherms, determined at $-196{ }^{\circ} \mathrm{C}$ in a Quantachrome NOVA 4200e multistation apparatus. Samples were previously degassed at $150{ }^{\circ} \mathrm{C}$ for $3 \mathrm{~h}$.

The particle size distributions were measured in a Coulter LS 230 equipment.

High Resolution Transmission Electron Microscopy (HRTEM) measurements were performed on a JEOL2010F instrument, with $0.19 \mathrm{~nm}$ spatial resolution at Scherzer defocus conditions. 
The surface chemistry was characterized by temperature programmed desorption (TPD) analysis. $\mathrm{CO}$ and $\mathrm{CO}_{2}$ TPD profiles were obtained with a fully automated AMI 300 Catalyst characterization apparatus (Altamira Instruments) connected to a Dycor Dymaxion Mass Spectrometer. Each sample $(0.100 \mathrm{~g})$ was heated up to $1100{ }^{\circ} \mathrm{C}$ at 5 ${ }^{\circ} \mathrm{C} / \mathrm{min}$ using a constant flow rate of helium equal to $25 \mathrm{~cm}^{3}(\mathrm{STP}) / \mathrm{min}$. For quantification of the $\mathrm{CO}$ and $\mathrm{CO}_{2}$ released during the analyses, calibration of these gases was carried out at the end of each experiment.

The XPS analyses were performed using a Kratos AXIS Ultra HSA, with VISION software for data acquisition and CASAXPS software for data treatment. The analyses were carried out with a monochromatic Al Ka X-ray source (1486.7 eV), operating at 15 kV (90 W), in FAT (Fixed Analyser Transmission) mode, with a pass energy of $40 \mathrm{eV}$ for regions $\mathrm{ROI}$ and $80 \mathrm{eV}$ for survey. Data acquisition was performed at a pressure lower than $10^{-6} \mathrm{~Pa}$, and a charge neutralisation system was used. Modelling of the spectra was performed using the XPSPEAK4.1 program, in which the peaks were fitted with a Gaussian-Lorentzian function using a Shirley type background subtraction.

\subsection{Catalytic tests}

The ozonation experiments were carried out in a laboratory-scale reactor (ca. $1 \mathrm{~L}$ ) equipped with stirring and a recirculation jacket. Ozone was produced from pure oxygen in a BMT 802X ozone generator. The concentration of ozone in the gas phase was monitored with a BMT 964 ozone analyser. Ozone leaving the reactor was removed in a series of gas-washing bottles filled with potassium iodide (KI) solution.

In each experiment the reactor was filled with $700 \mathrm{~mL}$ of oxalic acid solution with a concentration of $1 \mathrm{mM}$, at the natural $\mathrm{pH}$ (around 3). The solution was prepared from ultrapure water obtained in a Milli-Q Millipore system. In the catalytic ozonation experiments, $100 \mathrm{mg}$ of MWCNT were introduced in the reactor. The experiments were performed at constant flow rate $\left(150 \mathrm{~cm}^{3}\right.$ (STP)/min) and constant inlet ozone concentration $\left(50 \mathrm{~g} / \mathrm{m}^{3}(\mathrm{STP})\right)$. The agitation was maintained constant at $200 \mathrm{rpm}$. Some experiments were performed in duplicate and the average deviations were lower than $\pm 2 \%$.

For comparative purposes, both adsorption on selected samples and ozonation experiments in their absence (single ozonation) were performed in the same system, under identical experimental conditions. 
Samples were collected using a syringe at selected times and centrifuged for further analysis. The concentration of oxalic acid was followed by HPLC using a Hitachi Elite LaChrom HPLC equipped with a diode array detector. The stationary phase was a BIO-RAD Aminex HPX $87 \mathrm{H}(300 \mathrm{~mm} \times 7.8 \mathrm{~mm})$ working at room temperature. Analyses were carried out under isocratic elution with a solution of $\mathrm{H}_{2} \mathrm{SO}_{4} 4 \mathrm{mM}$ at a flow rate of $0.6 \mathrm{~mL} / \mathrm{min}$. The retention time for oxalic acid was $7.2 \mathrm{~min}$ and the wavelength of $210 \mathrm{~nm}$ was used for quantitative measurements. Six point calibration curves $(0.05-1 \mathrm{mM})$ were considered. Linear responses were obtained in this range. The $R^{2}$ value of calibration line was 0.99989 , the limit of quantification (LOQ) was $0.0097 \mathrm{mM}$ and the limit of detection (LOD) was $0.00096 \mathrm{mM}$.

\section{Results and discussion}

\subsection{Materials characterization}

Fig. 1A shows that the pristine MWCNT are formed by well-defined graphitic layers. This sample is formed by several aggregates of tubes highly entangled, curved and twisted with each other (data not shown). This high entanglement was markedly reduced after ball-milling. Fig. 1B shows the evidences of CNT damage due to the ballmilling treatment, which gradually lead to shortened CNT with the increase of the ballmilling time by breaking up the tubes. Similar results were reported in the literature [18, 19]. In addition, to clearly show that the ball-milling process is highly effective in disentangling and shortening MWCNT, TEM characterization demonstrate that open MWCNT are present in the samples obtained using high milling times (240 and 360 $\min )$.

The evolution of the surface area and particle size of the MWCNT samples with the ball-milling time, for the vibration frequency of 15 vibrations/s, is represented in Fig. 2 . The surface area remains practically constant (within the experimental error) until 60 min, increasing after that time. Thus, the specific surface area of the samples increases from $283 \mathrm{~m}^{2} / \mathrm{g}$ to a maximum of $326 \mathrm{~m}^{2} / \mathrm{g}$ after $240 \mathrm{~min}$, slightly decreasing thereafter. The increase in the surface area, corresponding to the first $240 \mathrm{~min}$, can be attributed to the opening or also breaking of the nanotubes during milling, in good concordance with the HRTEM results [20]. The slight BET decrease observed for higher times is probably due to twisting, bending and crushing of some tubes, which may partially block the access of nitrogen molecules to the inner part of those tubes. 
Pierard et al. [4] applied ball-milling to single-walled carbon nanotubes and also observed an increase of the surface area for the first $2 \mathrm{~h}$ of process due to the opening of the nanotubes during the milling, whereas after that time the surface area decreased due to compaction.

Fig. 2 also shows the evolution of the mode of particle size distribution with the milling time, for the vibration frequency of 15 vibrations/s. An opposite trend to the evolution of the surface area was observed. In this case, the particle size of the entanglements significantly decreases until $50 \mu \mathrm{m}$ after $240 \mathrm{~min}$ of milling, increasing thereafter. The decrease is related to the cut of the nanotubes, since the length became shorter by increasing the milling time. The increase of the particle size after $240 \mathrm{~min}$ may be due to the formation of agglomerates.

The effect of ball-milling vibration frequency was evaluated for the ball-milling time of $30 \mathrm{~min}$, and it was observed that the increase in the vibration frequency slightly increases the surface area (for values higher than 15 vibrations/s) and significantly decreases the particle size (Table 1). Thus, it seems that the milling vibration frequency has a similar effect on the change of the textural properties than the milling time.

Carbon nanotubes do not present significant amounts of oxygenated surface groups and ball-milling did not increase the functionalization of the surface. The TPD profiles (not shown) of all the milled samples are very similar to that determined for the original MWCNT. Comparable results were also obtained by Solhy et al. [21].

XPS analysis also revealed that the amounts of carbon and oxygen on the surface remain practically constant (Table 2 ) for the ball-milling times studied. Thus, it can be concluded that, under the experimental conditions used, ball-milling does not introduce oxygen-containing surface groups.

In summary, ball-milling influences the textural and morphological properties of carbon nanotubes, while their surface chemistries remain practically unchanged. On the other hand, Li et al. [18] investigated the influence of ball-milling on the structural integrity of a MWCNT sample by Raman spectroscopy and observed no differences between the pristine sample and the milled ones, demonstrating that the structural integrity of carbon nanotubes is not affected by ball-milling.

\subsection{Catalytic tests}


The activity of the samples was evaluated in the catalytic ozonation of oxalic acid at natural pH (approximately 3). Oxalic acid has been identified among the most common oxidation products from organic pollutants degradation; additionally, it is refractory to single ozonation. Several catalysts were shown to improve oxalic acid ozonation in aqueous solution, as reported in the literature [8,11, 22-25]. Ozonation of oxalic acid leads directly to mineralization, i.e., there is no formation of organic intermediates.

Fig. 3 shows the results obtained during the catalytic and non-catalytic ozonation of oxalic acid, using the MWCNT milled at different times but at constant vibration frequencies (15 vibrations/s). Ball-milling of MWCNT (even for only $5 \mathrm{~min}$ ) leads to an increase of the catalyst performance in the ozonation of oxalic acid. The MWCNT performances increase with the milling time up to $240 \mathrm{~min}$, and then slightly decrease. Thus, the samples milled during 120 and 240 min are the best catalysts, which may be explained by the high specific surface areas and small particle sizes of the agglomerates, where ozone and oxalic acid can adsorb and react. These results are in agreement with those obtained in a previous study [11], where it was concluded that catalytic ozonation of oxalic acid is favoured by MWCNT with high specific surface areas. The decrease in the performance of the sample milled during $360 \mathrm{~min}$ can be justified by the decrease in the specific surface area due to the twisting, bending and crushing of some tubes, which may partially block the access of ozone and oxalic acid to the tubes.

The first 30 min of the experimental curves in Fig. 3 suggest a zero-order reaction with respect to oxalic acid, which is in agreement with the results obtained in a previous study [11]. According to this kinetic model, the evolution of oxalic acid concentration during single ozonation is described by the following equation:

$$
-\frac{d C_{\text {oxalic acid }}}{d t}=k_{\text {hom }}
$$

where $k_{\text {hom }}\left(\mathrm{mmol} \mathrm{L}^{-1} \mathrm{~min}^{-1}\right)$ represents the zero-order apparent rate constant and $C_{\text {oxalic acid }}\left(\mathrm{mmol} \mathrm{L}^{-1}\right)$ is the concentration of oxalic acid in each instant. Integration of Equation (1), considering $C_{\text {oxalic acid }}=C_{\text {oxalic acid, } 0}$ when $t=0$, leads to:

$$
\frac{C_{\text {oxalic acid }}}{C_{\text {oxalic acid }, 0}}=1-\frac{k_{\text {hom }}}{C_{\text {oxalic acid }, 0}} t
$$


In the presence of MWCNT, both homogeneous and heterogeneous degradation occur. Thus, the oxalic acid removal rate is the sum of the two contributions. Therefore,

$$
-\frac{d C_{\text {oxalic acid }}}{d t}=\left(k_{\text {hom }}+k_{\text {het }}\right)
$$

where $k_{\text {het }}\left(\mathrm{mmol} \mathrm{L}^{-1} \mathrm{~min}^{-1}\right)$ represents the zero-order apparent rate constant for the catalytic degradation. Integration of Equation (3), considering $C_{\text {oxalic acid }}=C_{\text {oxalic acido }}$ when $t=0$, leads to:

$$
\frac{C_{\text {oxalic acid }}}{C_{\text {oxalic acid }, 0}}=1-\frac{k_{\text {hom }}+k_{\text {het }}}{C_{\text {oxalic acid }, 0}} t
$$

Apparent zero-order rate constant values for heterogeneous catalytic ozonation were calculated. In the fitting procedure followed, the value of $k_{\text {hom }}$ previously calculated was fixed $\left(1.22 \pm 0.05 \mathrm{mmol} \mathrm{L}^{-1} \mathrm{~min}^{-1}\right)[11]$.

In order to evaluate the influence of the particle size of samples in the mineralization of oxalic acid, $k_{\text {het }} / S_{\mathrm{BET}}$ is plotted against particle size (see black dots in Fig. 4). The correlation between the zero-order heterogeneous apparent rate constants normalized by $S_{B E T}$ and particle size of the MWCNTs agglomerates is significant at the $1 \%$ level. In general, the trend of the catalytic activity for the mineralization of oxalic acid follows the decrease of particle size of the agglomerates.

The effect of the ball-milling vibration frequency (10,15 and 20 vibrations/s) in the MWCNT performance for ozonation of oxalic acid was also evaluated for the sample milled during $30 \mathrm{~min}$. Fig. 5 shows that the increase in the vibration frequency also increases the catalytic performance of MWCNT, because the surface area also increases and the particle size of the agglomerates decreases (see Table 1). Nevertheless, the major difference in the oxalic acid removal is observed when the vibration frequency increases from 10 to 15 vibrations/s. In Fig. 4 the white dots, which correspond to the samples milled during $30 \mathrm{~min}$ at different vibration frequencies (10 and 20 vibrations/s), corroborate the determined correlation between the catalytic activity for the mineralization of oxalic acid and the particle size of the agglomerates.

In order to evaluate the adsorption capacity of the samples towards oxalic acid, an adsorption experiment on the sample BM_120_15 was also carried out, and it was concluded that adsorption on MWCNT scarcely contributes to the removal of oxalic acid compared to catalytic ozonation. 


\section{Conclusions}

The modifications performed on carbon nanotubes by ball-milling have a significant influence on their textural and morphological properties. The surface area increases, whereas the particle size of agglomerates decreases with the ball-milling time until 240 min for 15 vibrations/s.

XPS and TPD data show that the functionalization of the surface is not achieved by ball-milling.

The prepared samples were used as catalysts for the ozonation of oxalic acid. The modifications performed on carbon nanotubes have a significant influence on the catalytic efficiency, partially explained by the changes on their textural properties. The catalytic process is favoured by MWCNT with high specific surface areas and smaller lengths.

Ball-milling is an effective method to increase the performance of MWCNT as catalysts in ozonation process.

\section{Acknowledgments}

This work was supported by projects: FREECATS, European Union 7th FP, grant \# 280658; PEst-C/EQB/LA0020/2013 financed by FCT - Fundação para a Ciência e a Tecnologia and FEDER through Program COMPETE and by QREN, ON2 and FEDER (Project NORTE-07-0162-FEDER-000050). O.S.G.P. Soares and A.G. Gonçalves acknowledge grants received from FCT (SFRH/BPD/80435/2011 and SFRH/BPD/ 95538/2013, respectively).

\section{References}

[1] P. Serp, in: P. Serp, J.L. Figueiredo (Eds.), Carbon materials for catalysis, Jonh Wiley \& Sons, Inc.: Hoboken, New Jersey, 2009.

[2] J.H. Ahn, H.S. Shin, Y.J. Kim, H. Chung, J. Alloy Compd. 434 (2007) 428-432.

[3] W.M. Tucho, H. Mauroy, J.C. Walmsley, S. Deledda, R. Holmestad, B.C. Hauback, Scripta Mater. 63 (2010) 637-640.

[4] N. Pierard, A. Fonseca, J.F. Colomer, C. Bossuot, J.M. Benoit, G. Van Tendeloo, J.P. Pirard, J.B. Nagy, Carbon 42 (2004) 1691-1697.

[5] J.Y. Huang, H. Yasuda, H. Mori, Chem. Phys. Lett. 303 (1999) 130-134.

[6] Y.B. Li, B.Q. Wei, J. Liang, Q. Yu, D.H. Wu, Carbon 37 (1999) 493-497. 
[7] Y. Oh, J. Choi, Y. Kim, K. Kim, S. Baik, Scripta Mater. 56 (2007) 741-744.

[8] P.C.C. Faria, J.J.M. Órfão, M.F.R. Pereira, Appl. Catal. B-Environ. 79 (2008) 237-243.

[9] A.G. Gonçalves, J.J.M. Órfão, M.F.R. Pereira, J. Hazard. Mater. 239-240 (2012) 167-174.

[10] A.G. Gonçalves, J.J.M. Órfão, M.F.R. Pereira, Catal. Commun. 35 (2013) 8287.

[11] A.G. Gonçalves, J.L. Figueiredo, J.J.M. Órfão, M.F.R. Pereira, Carbon 48 (2010) 4369-4381.

[12] Z.-Q. Liu, J. Ma, Y.-H. Cui, B.-P. Zhang, Appl. Catal. B-Environ. 92 (2009) 301306.

[13] Z.-Q. Liu, J. Ma, Y.-H. Cui, L. Zhao, B.-P. Zhang, Appl. Catal. B-Environ. 101 ( 2010) 74-80.

[14] Z.-Q. Liu, J. Ma, Y.-H. Cui, I. Zhao, B.-P. Zhang, Sep. Purif. Technol. 78 (2011) 147-153.

[15] A.G. Gonçalves, J.J.M. Órfão, M.F.R. Pereira, Appl. Catal. B-Environ. 140-141 (2013) 82-91.

[16] X. Fan, J. Restivo, J.J.M. Órfão, M.F.R. Pereira, A.A. Lapkin, Chem. Eng. J. 241 (2014) 66-76.

[17] F.J. Béltran, F.J. Rivas, L.A. Fernandez, P.M. Alvarez, R. Montero-de-Espinosa, Ind. Eng. Chem. Res. 41 (2002) 6510-6517.

[18] F. Li, Y. Lu, L. Liu, L. Zhang, J. Dai, J. Ma, Polymer 54 (2013) 2158-2165.

[19] A. Kukovecz, T. Kanyo, Z. Konya, I. Kiricsi, Carbon 43 (2005) 994-1000.

[20] Z. Konya, J. Zhu, K. Niesz, D. Mehn, I. Kiricsi, Carbon 42 (2004) 2001-2008.

[21] A. Solhy, B.F. Machado, J. Beausoleil, Y. Kihn, F. Gonçalves, M.F.R. Pereira, J.J.M. Orfão, J.L. Figueiredo, J.L. Faria, P. Serp, Carbon 46 (2008) 1194-1207.

[22] R. Andreozzi, A. Insola, V. Caprio, R. Marotta, V. Tufano, Appl. Catal. A-Gen. 138 (1996) 75-81.

[23] F.J. Beltrán, F.J. Rivas, R. Montero-de-Espinosa, Appl. Catal. B-Environ., B 47 (2004) 101-109.

[24] P.C.C. Faria, J.J.M. Órfão, M.F.R. Pereira, Catal. Commun. 9 (2008) 21212126.

[25] C.A. Orge, J.P.S. Sousa, F. Gonçalves, C. Freire, J.J.M. Órfão, M.F.R. Pereira, Catal. Lett. 132 (2009) 1-9. 


\section{Figure captions}

Fig. 1 - Representative HRTEM images of the pristine sample (A) and after 30 (B), 240 (C) and 360 (D) minutes of milling at a vibration frequency of 15 vibrations/s.

Fig. 2 - Evolution of the surface area and mode of particle size distribution of MWCNT samples with the milling time, for the vibration frequency of 15 vibrations/s.

Fig. 3 - Evolution of the dimensionless concentration of oxalic acid at natural $\mathrm{pH}(\sim 3)$ during ozonation in the absence and presence of ball-milled MWCNT at different times $\left(\mathrm{C}_{0}=1 \mathrm{mM}, \mathrm{MWCNT}=0.14 \mathrm{mg} / \mathrm{L}\right)$.

Fig. 4 - Correlation of the normalized rate constants for the heterogeneous degradation of oxalic acid $\left(\mathrm{k}_{\text {het }} / \mathrm{S}_{\mathrm{BET}}\right)$ with the particle size of the MWCNTs agglomerates. (black dot - samples milled at 15 vibrations/s during different times; white dot - samples milled during $30 \mathrm{~min}$ at different vibration frequencies).

Fig. 5 - Evolution of the dimensionless concentration of oxalic acid at natural $\mathrm{pH}(\sim 3)$ during ozonation in the absence and presence of MWCNT ball-milled during 30 min at different vibration frequencies (10,15 and 20 vibrations $/ \mathrm{s})\left(\mathrm{C}_{0}=1 \mathrm{mM}, \mathrm{MWCNT}=0.14\right.$ $\mathrm{mg} / \mathrm{L})$. 


\section{Tables}

Table 1 - Surface area and mode of particle size distribution of the MWCNT ball milled during 30 min for different vibration frequencies.

\begin{tabular}{lcccc}
\hline Sample & BM_0 & BM_30_10 & BM_30_15 & BM_30_20 \\
\hline BET $\left(\mathbf{m}^{2} / \mathbf{g}\right)$ & 283 & 286 & 282 & 299 \\
\hline Particle size $(\mu \mathrm{m})$ & 684 & 296 & 140 & 46 \\
\hline
\end{tabular}


Table 2 - Surface composition by XPS.

\begin{tabular}{lcc}
\hline Sample & C (At\%) & O (At\%) \\
\hline BM_30_15 & 99.4 & 0.6 \\
BM_120_15 & 99.5 & 0.5 \\
BM_240_15 & 99.4 & 0.6 \\
BM_360_15 & 99.4 & 0.6
\end{tabular}


Figures

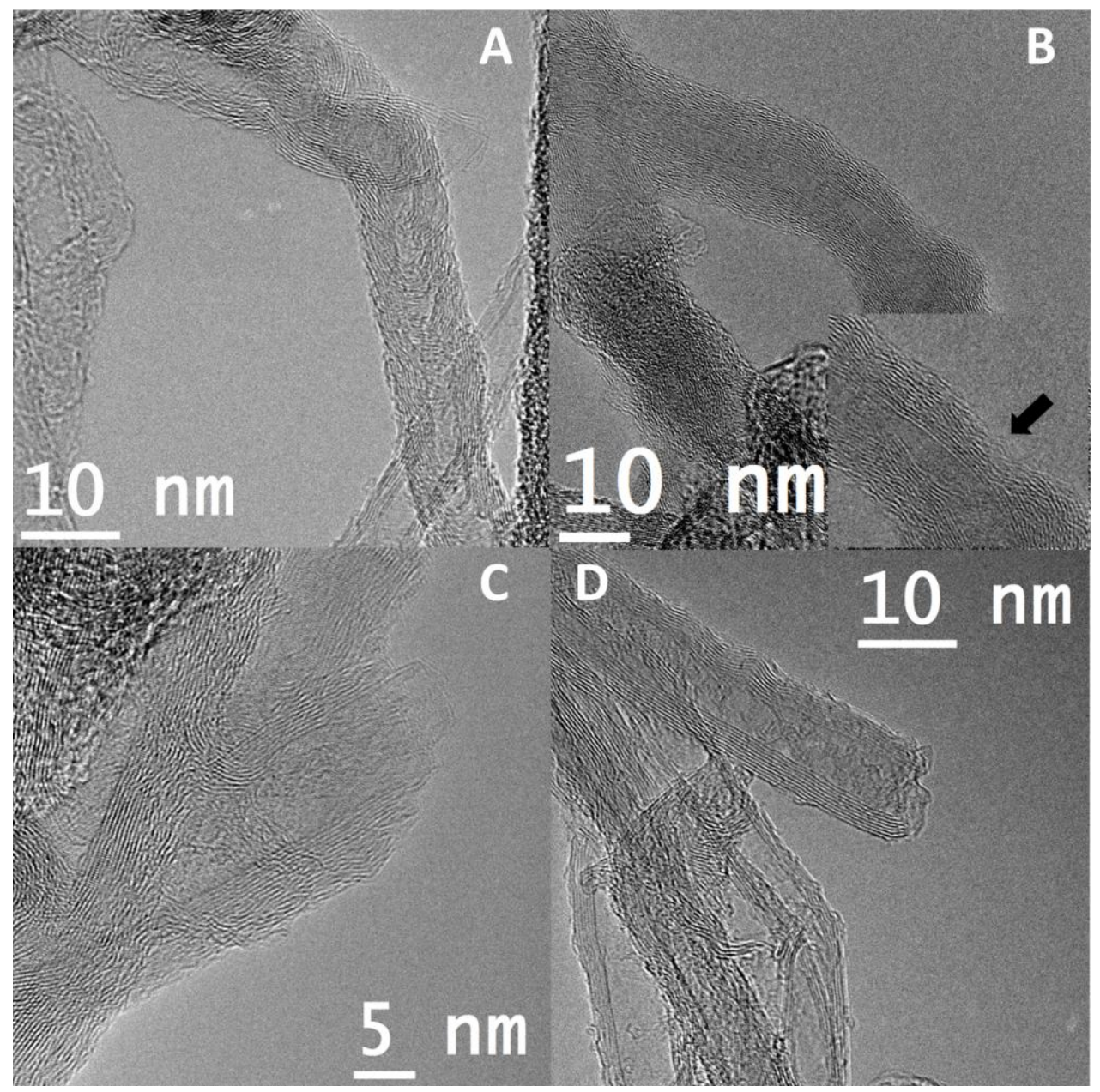

Fig. 1 


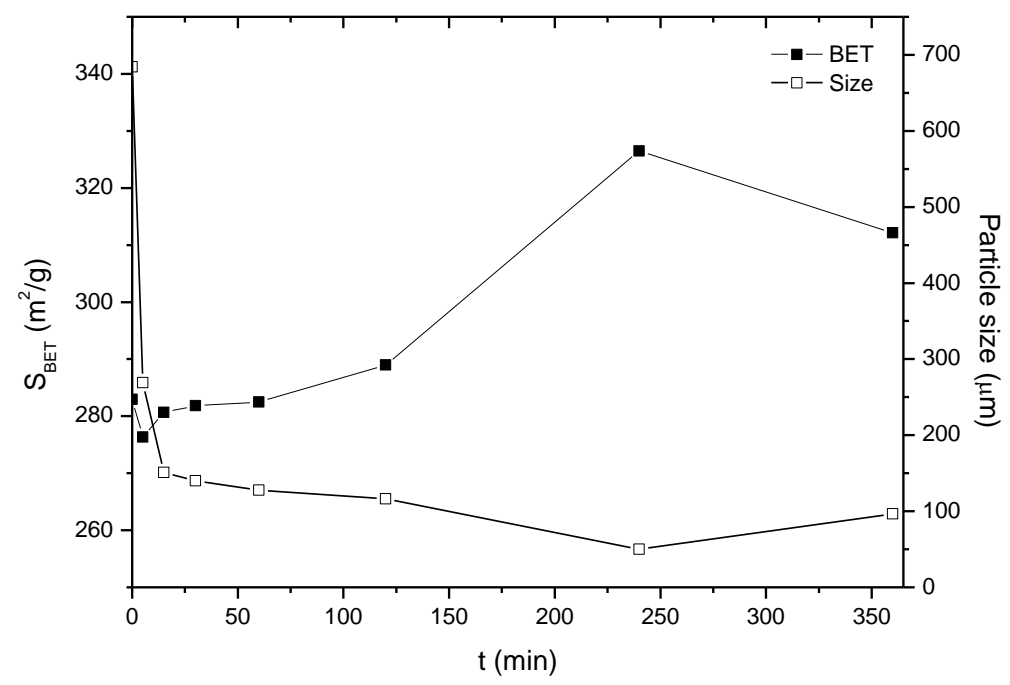

Fig. 2 


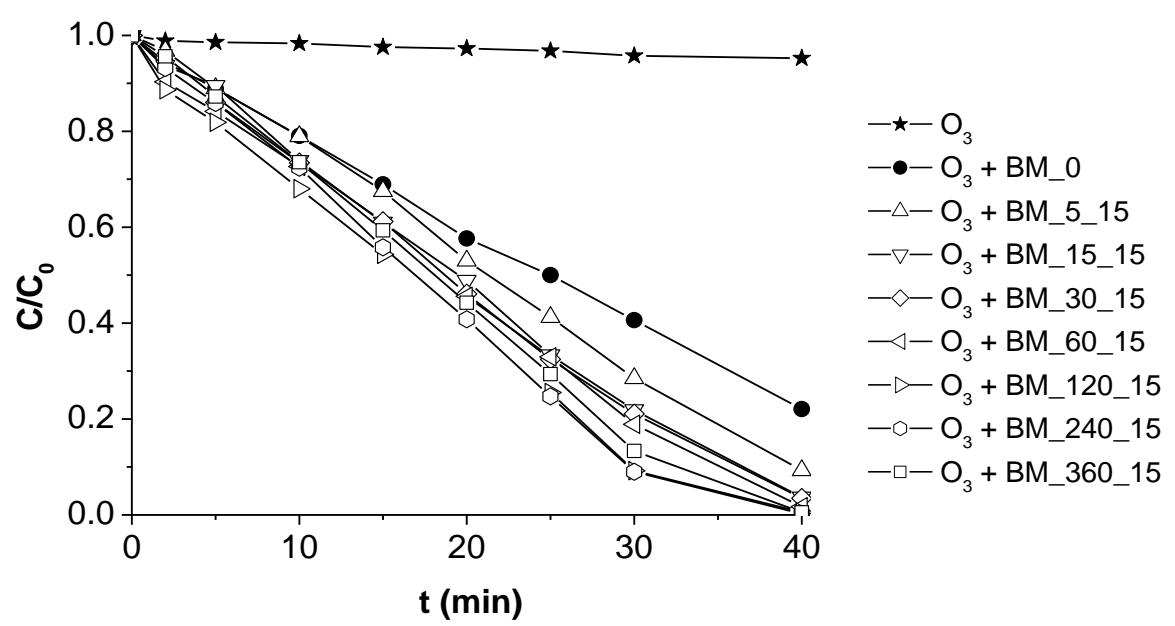

Fig. 3 


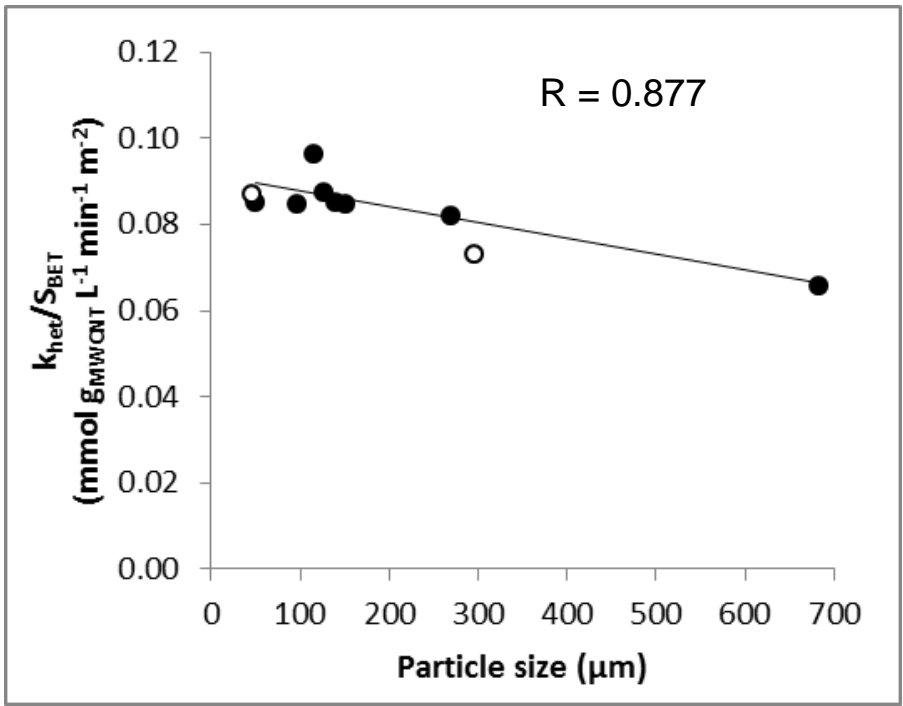

Fig. 4 


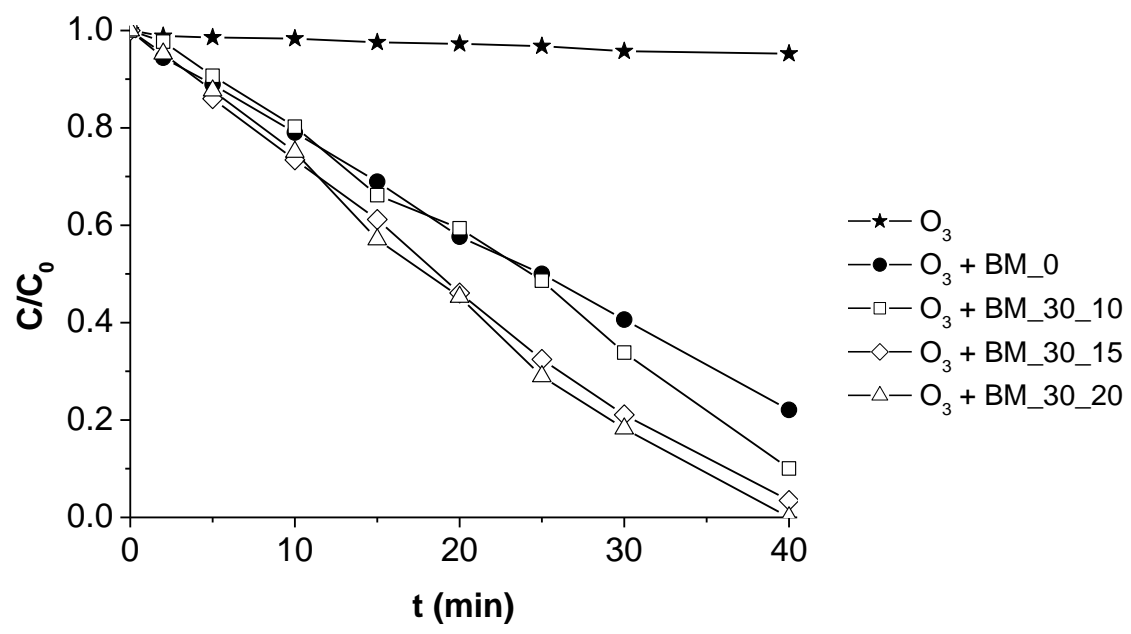

Fig. 5 


\section{Ball-milling}

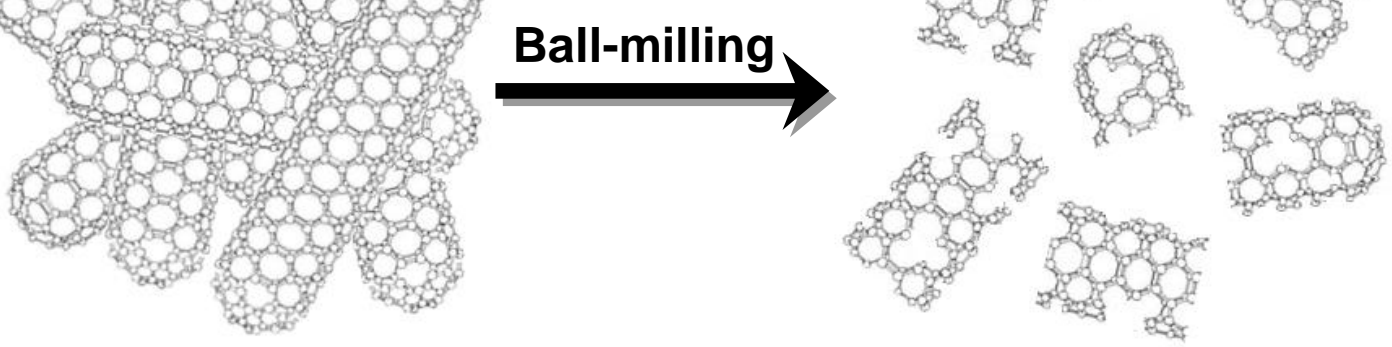

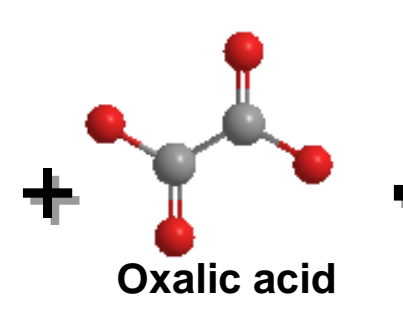

$\stackrel{\mathrm{o}_{3}}{\longrightarrow} \begin{gathered}\mathrm{CO}_{2} \\ + \\ \mathrm{H}_{2} \mathrm{O}\end{gathered}$ 